\title{
Enzyme-mediated hydrogel encapsulation of single cells for high-throughput screening and directed evolution of oxidoreductases
}

Rosario Vanella ${ }^{1,2}$, Duy Tien Ta ${ }^{1,2,3}$, and Michael A. Nash ${ }^{1,2 *}$

${ }^{1}$ Department of Chemistry, University of Basel, 4058 Basel, Switzerland.

${ }^{2}$ Department of Biosystems Science and Engineering, ETH Zurich, 4058 Basel, Switzerland.

${ }^{3}$ Current affiliation: A*STAR - Agency for Science, Technology and Research, 138632 Singapore.

* Correspondence to michael.nash@unibas.ch 
Keywords: directed evolution, glucose oxidase, cell encapsulation, hydrogels

Abstract: Directed evolution of oxidoreductases to improve their catalytic properties is being ardently pursued in the industrial, biotechnological, and biopharma sectors. Hampering this pursuit are current enzyme screening methods that are limited in terms of throughput, cost, time and complexity. We present a directed evolution strategy that allows for large-scale one-pot screening of glucose oxidase (GOx) enzyme libraries in well-mixed homogeneous solution. We used GOx variants displayed on the outer cell wall of yeasts to initiate a cascade reaction with horseradish peroxidase (HRP), resulting in peroxidase-mediated phenol cross-coupling and encapsulation of individual cells in well-defined fluorescent alginate hydrogel shells within $\sim 10$ minutes in mixed cell suspensions. Following application of denaturing stress to whole-cell GOx libraries, only cells displaying GOx variants with enhanced stability or catalytic activity were able to carry out the hydrogel encapsulation reaction. Fluorescence activated cell sorting was then used to isolate the enhanced variants. We characterized three of the newly evolved Aspergillus niger GOx enzyme sequences and found up to $\sim 5$-fold higher specific activity, enhanced thermal stability, and differentiable glycosylation patterns. By coupling intracellular gene expression with the rapid formation of an extracellular hydrogel capsule, our system improves high-throughput screening for directed evolution of $\mathrm{H}_{2} \mathrm{O}_{2}$-producing enzymes many fold. 


\section{Introduction}

Reaction compartmentalization at the cellular length scale is of high interest for directed evolution (Fischlechner et al., 2014; Sjostrom et al., 2014; Tawfik and Griffiths, 1998). The goal in such experiments is to combine the generation of genetic diversity together with screening or selection for enhanced phenotypic traits. Such approaches have been widely used for improving the performance of affinity proteins such as antibodies, as well as catalytic enzymes (Arnold, 2018; Denard et al., 2015; Jeschek et al., 2016; Packer and Liu, 2015; Powell et al., 2001; Taylor et al., 2001). Typically, screening for improved enzymatic activity is achievable only at low-to-medium throughput $\left(<10^{4}\right.$ variants $)$ because each enzyme variant has to be assayed individually, which can be time consuming and costly. Typically, each clone is isolated and grown in a separate well of a multi-well plate or in a separate colony on an agar plate. Each individual wells or colony then serves as reaction compartment which restricts diffusion of the enzyme reaction products localizing them to the site of production. This spatial co-localization allows for the necessary genotype-phenotype linkage for directed evolution to proceed. However, the requirement of separating genetic clones into different reaction compartments severely restricts the throughput of enzyme screens. This ultimately limits the size of the genetic libraries that can be screened, slowing down the evolutionary process. To address this shortcoming, various methods for microscale reaction compartmentalization have been developed, including single and double emulsions (Griffiths and Tawfik, 2006), and multi-phase microfluidic systems for droplet generation (Colin et al., 2015; Kintses et al., 2012). Multi-phase systems, however, may be cumbersome to implement, often requiring microfabricated devices and precise flow rate control. Furthermore, many droplet systems rely on cell-free transcription/translation, which may not be capable of glycosylation and other post-translational modifications that can affect protein activity, or may lack folding chaperones.

The cell surface has also been utilized as a quasi-compartment. In such systems, bacteria can be labelled with fluorescent molecules or hydrogels when a target reaction occurs inside the cell (Lülsdorf et al., 2015), or when displayed enzymes covalently modify the cell surface. Such approaches have been used, for example, to evolve peptide ligases (Chen et al., 2011) and oxidoreductases using a tyramide-fluorescein assay (Lipovsek et al., 2007; Ostafe et al., 2014). Although covalent cell-surface modification with small molecules offers some improvements, such systems can suffer from cross-reactivity between positive and negative cells, increasing the false-positive rate. 
Directed evolution of accelerated or stabilized GOx variants is of considerable interest for the food and textile industries, as well as for blood glucose detection (Wong et al., 2008), deoxygenation of buffers for single-molecule fluorescence applications (Aitken et al., 2008), and oxygen inhibitor removal for radical polymerization (Chapman et al., 2014). Recently we reported a new method for single-cell encapsulation in hydrogel capsules that relied on a glucose oxidase (GOx) and horseradish peroxidase (HRP) enzyme cascade to cross-link phenol moieties grafted onto alginate and chitosan macromonomers (Vanella et al., 2019). The system we reported was made possible by GOx initiator enzymes that were synthesized by the cells from single-copy plasmids carrying the GOx gene, and surface-displayed on the outer cell wall. A competing approach has also been reported to produce hydrogels using a GOx cascade with Fenton's reagent, which can produce hydroxyl radicals for polymerization of vinylated compounds and fluorophores (Malinowska et al., 2014; Malinowska et al., 2015; Malinowska and Nash, 2016; Pitzler et al., 2014). Here, we report the utilization of the GOx-mediated cell encapsulation system for directed evolution of GOx. We utilized the GOx/HRP cell encapsulation system for screening of residual GOx activity following denaturing stress applied to a library of mutant GOx enzymes. Our strategy utilizes enzymatic radical polymerization to form a well defined uniform hydrogel shell around cells presenting active variants of the target enzyme. The 3D conformal nature of the hydrogel shells and the short lifetimes of the radical cross-linking species are features that allowed for essentially zero cross-reactivity (i.e., no false positive labelling) under our optimized conditions. The resultant GOx variants were isolated in soluble form and characterized using biophysical assays to shed light on the mechanisms involved in thermal and catalytic enhancement.

\section{Materials and Methods}

Materials. All the chemicals used in this work were purchased from Sigma Aldrich if not otherwise specified. The primary and secondary antibodies were purchased from Thermo Fisher Scientific. Restriction enzymes were purchased from New England Biolabs. Sodium Alginate (Viscosity 1\%: 100 - $200 \mathrm{mPa} \cdot \mathrm{s}$ ) was purchased from Duchefa Biochemie. 
Amplification, cloning, and yeast display of WT GOx. The GOx wild type gene was amplified from the genome of Aspergillus niger strain 4247 (LGC Standards) using the primers F1 and R1 (Table 1), and cloned using BamHI and $\mathrm{XhoI}$ restriction sites into the yeast plasmid pYD1 for protein display (gift from Dane Wittrup, Addgene plasmid \#73447) (Kieke et al., 1997). After sequence confirmation, the plasmid pYD1-GOx was transformed into Saccharomyces cerevisiae EBY100 following a typical lithium acetate transformation (Gietz and Woods, 2002) procedure, followed by selection of positive colonies on SD agar 2\% (w/v) glucose plates lacking tryptophan (-Trp). Resulting colonies were cultivated in -Trp liquid medium with $2 \%$ glucose for 24 hours at $30^{\circ} \mathrm{C}$ to an $\mathrm{OD}_{600} \sim 8$ with continuous shaking at $200 \mathrm{rpm}$. Protein expression and display was then induced by transferring the culture at a starting $\mathrm{OD}_{600} \sim 0.4$ to fresh liquid medium lacking tryptophan containing $0.2 \%(\mathrm{w} / \mathrm{v})$ glucose and $1.8 \%(\mathrm{w} / \mathrm{v})$ galactose, and shaking for 24 hours at $30^{\circ} \mathrm{C}$.

Preparation of fluorescent alginate with phenols groups. Alginate macromonomers grafted with phenol moieties and aminofluorescein was prepared through carbodiimide activation chemistry as previously reported (Sakai and Kawakami, 2007; Vanella et al., 2019). Sodium alginate (avg. $\mathrm{M}_{\mathrm{W}}$ 70,000 Da) was dissolved in 50 mM MES buffer $\mathrm{pH} 6(10 \mathrm{mg} / \mathrm{mL})$, followed by addition of tyramine hydrochloride, NHS, and EDC at concentrations of 7, 1.2, and $3.9 \mathrm{mg} / \mathrm{mL}$, respectively. Finally, $0.25 \mathrm{mg} / \mathrm{mL}$ of 6 -aminofluorescein was added and the reaction was allowed to proceed at room temperature for $\sim 18$ hours with stirring. The modified alginate was then precipitated dropwise into an $80 \%$ ethanol solution in water, followed washing with $80 \%$ ethanol. The final product was dissolved in water prior to lyophilization. Modification was confirmed through ${ }^{1} \mathrm{H}-$ NMR.

Cell encapsulation in fluorescent alginate hydrogels. Yeast cells in induction media displaying GOx were washed with $50 \mathrm{mM}$ sodium phosphate buffer $\mathrm{pH} 7.4$ and resuspended at $\mathrm{OD}_{600}=0.2\left(\sim 2 \cdot 10^{6}\right.$ cells $\left./ \mathrm{mL}\right)$. Glucose $(100 \mathrm{mM}), \mathrm{HRP}(4.5 \mu \mathrm{M})$ and modified alginate $(0.125 \%(\mathrm{w} / \mathrm{v}))$ were added. The reaction was gently mixed and incubated at room temperature for $10 \mathrm{~min}$, followed by four fold dilution by $50 \mathrm{mM}$ sodium phosphate buffer pH 7.4. Samples were then analyzed through fluorescence microscopy or flow cytometry. GOx mutant library construction by error prone PCR. A GOx mutant library with a medium mutation frequency (4.5-9 mutations/ kb) was prepared by amplifying the region between nucleotides 4 and 513 of the 
GOx wild type gene in pYD1 through error prone PCR (GeneMorph II, Agilent) using primers F2 and R2 (Table 1). The backbone of the recipient vector was amplified through PCR using primers F3 and R3 (Table 1). The error prone PCR product and the pYD1 linearized backbone were then co-transformed into EBY 100 an assembled as a complete plasmid in vivo via gap repair (Oldenburg et al., 1997). After culturing of the positive clones on selective medium agar plates, the colonies were collected and grown for 24 hours in liquid media prior to induction of GOx expression and display.

FACS-based screening. Yeast cells were sorted using a MoFLo XDP cell sorter from Beckman Coulter equipped with $488 \mathrm{~nm}$ and $561 \mathrm{~nm}$ lasers, and with a $100 \mu \mathrm{m}$ nozzle. Prior to sorting, GOx mutant libraries were treated with 5M guanidinium chloride for 10 minutes, washed 3 times, and stained with Propidium Iodide (final concentration of $4 \mu \mathrm{g} / \mathrm{mL}$ ), followed by washing. Next, the same PI-stained cells were used for the encapsulation reaction under the following conditions: $\sim 2 \cdot 10^{6}$ cells $/ \mathrm{mL}$ suspended in $50 \mathrm{mM}$ sodium phosphate buffer, $\mathrm{pH}$ 7.4. Glucose, HRP and modified alginate were used at final concentrations of $100 \mathrm{mM}$, $4.5 \mu \mathrm{M}$, and $0.125 \%(\mathrm{w} / \mathrm{v})$, respectively. All single-cell events showing positive signal for the encapsulation reaction (fluorescein fluorescent signal) and negative for the staining with Propidium Iodide were sorted in single-cell mode (Figure S1).

After sorting, single cells were cultured in liquid glucose medium lacking tryptophan for two days at $30^{\circ} \mathrm{C}$ and spotted on agar plates with $2 \%(\mathrm{w} / \mathrm{v})$ galactose lacking tryptophan in order to induce the GOx protein expression and display. After 2 days incubation at $30^{\circ} \mathrm{C}$ the colonies were used for an ABTS top-agar assay in order to test for the expression of GOx. The assay was performed by mixing $2 \%$ (w/v) agar with an equal volume of ABTS reaction solution containing $666 \mathrm{mM}$ Glucose, $14 \mathrm{mM}$ ABTS and $150 \mu \mathrm{g}$ HRP and by pouring the mixture directly onto the colonies. After a few minutes green halos were observed around the colonies expressing GOx. Furthermore, after culturing the cells in liquid SD glucose medium lacking tryptophan the plasmids were isolated using the Zymoprep ${ }^{\mathrm{TM}}$ Yeast Plasmid Miniprep II kit. The sequences of the GOx mutant genes were then obtained through Sanger sequencing.

Soluble protein expression and purification. Yeast colonies carrying the pYD1 vector with wild type or mutant GOx genes were grown in -Trp liquid medium with $2 \%(\mathrm{w} / \mathrm{v})$ glucose for 24 hours at $30^{\circ} \mathrm{C}$ with 
continuous shaking at $200 \mathrm{rpm}$. Protein expression and display was induced by transferring the cells at an initial $\mathrm{OD}_{600}$ of 0.4 to a -Trp liquid medium containing the $1.8 \%(\mathrm{w} / \mathrm{v})$ of galactose and $0.2 \%(\mathrm{w} / \mathrm{v})$ of glucose, and growing the cultures at $30^{\circ} \mathrm{C}$ while shaking at $200 \mathrm{rpm}$. After $24 \mathrm{~h}$, the cells were pelleted down and washed with $20 \mathrm{mM}$ Hepes buffer $\mathrm{pH} 8$ before being resuspended at an $\mathrm{OD}_{600}$ equal to $\sim 50$ in the same buffer containing $0.1 \mathrm{mM}$ of DTT. The DTT-reduction reactions were incubated for 2.5 hours at room temperature with gentle shaking in order to reduce the disulfide bonds between Aga2 and Aga1 proteins which are responsible for anchoring GOx on the yeast surface. Afterwards the cells were pelleted down and the supernatant was loaded on an HiTrap ion exchange column. Aga2-GOx WT and Aga2-GOx mutants (M1, M2, and M3) were eluted by applying a $\mathrm{NaCl}$ gradient from 0 to $1 \mathrm{M}$. The eluted proteins were collected in $1 \mathrm{ml}$ fractions and all samples were tested for GOx activity using an ABTS assay (see below). Eluted fractions containing functional GOx were isolated and concentrated through a $100 \mathrm{kDa}$ cutoff Vivaspin ultrafiltration column. Different GOx variants were compared in there native, denatured and deglycosylated using SDSPAGE. In order to cleave N-linked mannose and compare the proteins in their deglycosylated form, each protein $(1 \mu \mathrm{g})$ was denatured and treated with 1000 units of EndoH (NEB) enzyme at $37^{\circ} \mathrm{C}$ for $1 \mathrm{~h}$.

Enzyme kinetic studies. Kinetic analyses of each GOx variant in soluble form was performed using an ABTS assay with different concentrations of glucose from 0.4 to $50 \mathrm{mM}$. The other components of the reactions were 4.74 nM of Aga2-GOx WT or mutant enzyme, $4.5 \mu \mathrm{M}$ HRP, $2 \mathrm{mM}$ ABTS in $100 \mathrm{mM}$ Sodium Phosphate Buffer at $\mathrm{pH}$ 7.4. The concentration of HRP used in the kinetic reactions was $\sim 1000$ times higher than the GOx concentration and was experimentally confirmed not to limit the rate of the reaction. All kinetic studies were performed in triplicates by following the absorbance of the ABTS substrate at $405 \mathrm{~nm}$ following processing by the GOx/HRP cascade. Absorbance values were converted to rates of product formation $\left(\mu \mathrm{M} \mathrm{s}^{-}\right.$ $\left.{ }^{1} \mathrm{H}_{2} \mathrm{O}_{2}\right)$ using a standard curve. Enzyme kinetic data were fitted to the Michaelis-Menten equation using the GraphPad Prism 5 software in order to determine the $\mathrm{K}_{\mathrm{m}}$ and $k_{\text {cat }}$ values for each enzyme variant. The molar concentration of Aga2-GOx WT and M1, M2, and M3 mutants was set to $4.74 \mathrm{nM}$ for each reaction using the Lambert-Beer law and considering the extinction coefficient at $280 \mathrm{~nm}$ based on the amino acid sequence of the respective proteins. 
Thermostability studies. The thermostability of soluble wild-type and mutant GOx enzymes was determined by incubating $50 \mathrm{ng}$ of each enzyme in $50 \mathrm{mM}$ sodium phosphate buffer (pH 7.4) at increasing temperatures from 50 to 62.5 for 10 minutes. The sample was then cooled and residual activity of GOx was measured using the ABTS assay as described above. For each reaction the initial rate was calculated in the linear range of the curve. For each enzyme variant, the rate of the reaction catalyzed by that sample incubated at $50^{\circ} \mathrm{C}$ was considered $100 \%$ of activity; in order to calculate the residual activity, the initial reaction rates at the various temperatures were normalized to the initial rate at $50^{\circ} \mathrm{C}$ for the same protein. Additionally, temperaturedependent differential scanning fluorescence was performed using the Prometheus instrument (NanoTemper). Samples of $0.1 \mathrm{mg} / \mathrm{mL}$ wild-type or GOx enzyme were analyzed in microcapillaries in $50 \mathrm{mM}$ sodium phosphate buffer, $\mathrm{pH} 7.4$.

\section{Results and Discussion}

GOx is a $160 \mathrm{kDa}$ highly glycosylated homodimeric complex that binds 2 FAD cofactor molecules within a globular folded structure. During its catalytic cycle, GOx utilizes molecular oxygen as an electron acceptor, oxidizing $\beta$-D-glucose to D-gluconolactone and producing hydrogen peroxide as a byproduct (Swoboda and Massey, 1965) (Figure 1A). We developed the current system relying on GOx and HRP working in tandem as a bi-enzymatic initiation system for polymerization of phenolated fluorescent macromonomers (Sakai et al., 2012; Sakai et al., 2013; Shoda et al., 2016; Sigg et al., 2011; Uyama et al., 1997; Vanella et al., 2019; Zavada et al., 2016). To produce the macromonomers, we modified sodium alginate $\left(\mathrm{M}_{\mathrm{W}}=70,000 \mathrm{~g} / \mathrm{mol}\right)$ with tyramine and aminofluorescein (Figure 1B) (Liu et al., 2014; Sakai and Kawakami, 2007) using carbodiimide activation chemistry. ${ }^{1} \mathrm{H}-\mathrm{NMR}$ confirmed the presence of aromatic phenol and fluorescein groups in the resulting polymer (Vanella et al., 2019). The approach for directed evolution of GOx is presented in Figure 1C. We PCR amplified the full length GOx gene sequence from the genome of Aspergillus niger and cloned it into the pYD1 yeast display vector in frame with the a-agglutinin protein Aga2p. The sequence was confirmed by Sanger sequencing and the plasmid was transformed into S. cerevisiae EBY100 (Boder and Wittrup, 1997). EBY100 contains a genomic copy of Agalp under control of a strong galactose promoter (pGAL). The GOx gene was contained on an episomal pYD1 plasmid also under control of the pGAL promoter and located downstream and in frame with the Agalp domain. EBY100 is advantageous 
for GOx directed evolution because it supports glycosylation and can display large proteins (Gonzalez-Perez et al., 2012). Indeed, this strain was previously used for GOx directed evolution using a multi-phase system for reaction compartmentalization (Ostafe et al., 2014). By supplementing the growth media with galactose, we induced a chromosomal copy of Agalp and a plasmid copy of Aga2p-GOx. Immunostaining using antiXpress protein tag antibodies labeled with Alexa Fluor 555 was used to verify translocation and anchoring of Aga2p-GOx to Aga1p on the outer cell wall. Analytical flow cytometry indicated that $\sim 60 \%$ of cells in the population were fluorescently labeled, consistent with successful display of GOx. A positive result using an HRP/amplex red assay confirmed the activity of displayed GOx (data not shown).

To encapsulate individual yeast cells using the GOx/HRP enzyme cascade, cells displaying functional GOx homodimers $\left(2 \cdot 10^{6}\right.$ yeast cells $\left./ \mathrm{mL}\right)$ were suspended in $100 \mathrm{mM}$ glucose, $4.5 \mu \mathrm{M}$ HRP, and $0.125 \%$ $(\mathrm{w} / \mathrm{v})$ of phenolated alginate. Following 10 minutes of incubation in the encapsulation solution, $\sim 60 \%$ of cells showed positive fluorescent signals in the green channel due to the presence of fluorescein (Figure 2A) in the capsules. Confocal fluorescence microscopy (Figure 2B) indicated uniform and continuous fluorescent hydrogel shells encapsulating individual cells, $15-25 \mu \mathrm{m}$ in diameter (including the cell diameter). We found that in order for the hydrogel encapsulation reaction to remain localized at the cell surface, the cell concentration in the reaction medium must not be set too high. At cell concentrations $>1 \cdot 10^{7}$ cells $/ \mathrm{mL}$, the entire solution was found to cross-link and form a gel. At a cell concentration range of $2.5 \cdot 10^{6}-1 \cdot 10^{7}$ cells $/ \mathrm{mL}$, small hydrogel aggregates encapsulating multiple cells were observed. Maintaining cell concentrations at or below $2 \cdot 10^{6}$ cells $/ \mathrm{mL}$ resulted in singly encapsulated cells with no cross reactivity even after extended incubation. In order to avoid aggregation of the encapsulated cells post-polymerization, the reaction mixture was rapidly diluted 4-fold following the reaction time, and the encapsulated cell mixture was regularly agitated with a pipette prior to analysis by FACS. Centrifugation of the encapsulated cells was avoided.

In previous work (Vanella et al., 2019), we validated the hydrogel encapsulation reaction as a cell screening tool by screening cell mixtures of diluted GOx positive cells in a background of pYD1 empty plasmid-containing cells, and observing a direct correspondence of selected positive cell concentrations in FACS plots. Green fluorescent cells sorted in single-cell mode from a reference mixture containing $10 \%$ GOx positive cells were re-cultured without any noticeable effect of the gel capsules on cell growth rate, and all 
were found to be positive for GOx when tested using ABTS top agar assay. These results indicated there was a very low to zero background labeling of cells during the screening procedure, eliminating false positive events from the sorted cell mixtures.

We next implemented the hydrogel encapsulation system for the isolation of GOx variants with enhanced properties. We targeted mutagenesis to the N-terminus of GOx, which accounts for the dimer interface. We applied a random mutagenesis approach, generating a pool of GOx mutants through error prone PCR targeting the first 500 nucleotides of the gene. This mutagenized PCR product was then transformed directly into yeast together with the linearized pYD1 plasmid and assembled in vivo by gap repair. We estimated the size of the library by counting the number of colonies per area on a representative area of the agar plates and multiplying by the total area of all the plates, obtaining an approximate library size of one half million GOx variants $\left(\sim 0.5 \cdot 10^{6}\right)$. By sequencing the plasmids of 5 randomly selected clones from the yeast library, we calculated an average mutation frequency of 8 mutations per kb.

In order to screen the library, we disrupted the structure of GOx homodimers using high concentrations of gaunidinium hydrochloride $(\mathrm{GdnHCl})$. We found that short term exposure to $5 \mathrm{M} \mathrm{GdnHCl}$ followed by washing in PBS buffer irreversibly denatured the parent GOx enzyme resulting in complete inhibition of the cellular encapsulation reaction. Treatment of the yeast cells with $5 \mathrm{M} \mathrm{GdnHCl}$ additionally resulted in partial cell death, with $\sim 25 \%$ of the cells surviving and propagating in growth media without requiring plasmid extraction or re-transformation. This screening strategy allowed us to exclude clones that performed as well as or worse than wild type GOx, while maintaining a significant number of living cells capable of being isolated and expanded in culture. In the absence of $\mathrm{GdnHCl}$, we observed no adverse effects of the gel capsules on cell growth following encapsulation (Vanella et al., 2019). Encapsulated cells were able to easily break out of the gel capsules and propagate in growth media.

The screening procedure involved incubation of the mutant GOx library with 5M GdnHCl for 10 minutes, followed by washing and addition of hydrogel encapsulation reagents to the cell mixture in a one-pot reaction. This approach assayed for residual GOx activity following $\mathrm{GdnHCl}$ treatment, whereby the presence of the hydrogel shell was correlated with more active or more stable GOx variants displayed on the cell wall. All cells trapped in fluorescent alginate and not stained by propidium iodide (PI), a fluorescent dye used to 
label the dead cells, were isolated through single cell sorting and recultured for subsequent protein expression and characterization (Figure S1).

The ultrahigh throughput nature of the 10-min one-pot encapsulation method allowed the analysis of more than $5 \cdot 10^{6}$ library members in a single sorting session of less than 1 hour, providing $\sim 10$-fold coverage of the mutant library of size $0.5 \cdot 10^{6}$. Selected cells were re-cultured and tested individually to compare the stability and activity of the displayed GOx variants to the parent enzyme. Following screening, the residual activity of 27 mutants along with wild type GOx was first tested in the cell display format. Each isolated clone was induced for GOx expression and incubated at elevated temperature as follows. Each clone was exposed to 10 minutes of thermal stress at $70{ }^{\circ} \mathrm{C}$, followed by exposure to the hydrogel encapsulation reagents. The fraction of encapsulated cells was then analyzed using flow cytometry (data not shown). The three GOx mutants that performed best under thermal stress in the cell surface-based assay were then purified as soluble Aga2-GOx fusion proteins and further analyzed. The obtained parental Aga2-GOx and the three mutant Aga2GOx enzymes are denoted WT, and M1, M2, and M3, respectively. It was previously reported (Blazic et al., 2013) that Aga2-GOx fusion proteins produced using surface display in S. cerevisiae exhibited a $\sim 1.5$-fold decrease in catalytic turnover rate as compared with GOx lacking the Aga2 fusion domain. This prior work confirmed, however, that both an enhanced mutant and wild type GOx were affected equally by fusion with Aga2, indicating that detection of an improved GOx variant as an Aga2-fusion reflects improvement in the properties of the enzyme and not an artifact of the Aga2 fusion domain.

The three evolved mutants (M1, M2, M3) and WT enzyme were released from their respective cell surfaces using dithiothreitol (DTT) to reduce the disulfide bonds between Aga1p and Aga2p-GOx. Soluble Aga2-GOx was then purified from the reduced cell supernatants using ion exchange chromatography. The resulting proteins were tested for kinetic parameters using a cascade HRP/ABTS assay (Figure 3A). All three mutants exhibited improved activity (Figure 3B), with M1 having 4.9-fold greater catalytic efficiency. M3 exhibited the highest $k_{\mathrm{cat}}$ value, which was 3.96-fold higher than WT. The $K_{\mathrm{m}}$ values for M1, M2, and M3 were furthermore slightly lower than WT but not hugely improved. This was consistent with the selection step which was performed at a saturating substrate concentration of $100 \mathrm{mM}$ glucose.

Sequence analysis (Figure 3B) showed that the improvements in enzyme activity were achieved as a result of a single point mutation in the case of M1 and M3, or as the result of 2 mutations close together in 
primary sequence in the case of M2. Each mutant presented a mutation which replaced a Leucine with Proline in position 9 or 13. In addition, M2 contained an additional mutation that replaced the Alanine at position 16 with Threonine. The identified mutations were all located within the first 22 amino acids of the GOx protein leader peptide sequence. This region of the protein is cleaved off when the enzyme is expressed natively in $A$. niger. To the best of our knowledge, prior work on directed evolution of GOx in heterologous systems excluded the leader sequence, therefore the mutations identified here are newly reported sequences (Holland et al., 2012; Ostafe et al., 2014; Prodanovic et al., 2011; Zhu et al., 2007).

Thermostability of the evolved mutants was evaluated by measuring normalized initial substrate turnover rate following 10 minute heat shock (Figure 3C). All three enzymes showed improvement in thermostability, with the largest improvement occurring at $55{ }^{\circ} \mathrm{C}$, where the WT enzyme exhibited $59 \%$ residual activity while $\mathrm{M} 1, \mathrm{M} 2$, and $\mathrm{M} 3$ remained 74,73 , and 72\% active, respectively. Thermostability of WT, M1, M2 and M3 was further analyzed using nano differential scanning fluorescence (nanoDSF) (Figure 4). NanoDSF determines protein denaturation temperature by monitoring the normalized intrinsic fluorescence ratio $(350 \mathrm{~nm} / 330 \mathrm{~nm})$ excited at $280 \mathrm{~nm}$ as a function of temperature. The nanoDSF results showed two denaturation peaks occurring at $53^{\circ} \mathrm{C}$ and $61{ }^{\circ} \mathrm{C}$. For mutants $\mathrm{M} 1$ and $\mathrm{M} 3$, the peak at $61^{\circ} \mathrm{C}$ was significantly more prominent than the one at $53{ }^{\circ} \mathrm{C}$, indicating a larger fraction of the sample denatured at the higher temperature. For mutant M2, the peaks at $61{ }^{\circ} \mathrm{C}$ and $53{ }^{\circ} \mathrm{C}$ were equally prominent. For wild type by contrast, the peak at $53^{\circ} \mathrm{C}$ was the dominant peak. This result indicates that the mutants exhibit a thermally stabilized dimer conformation that outperforms WT. Combining this result with SDS-PAGE analysis (see below), we attributed the lower temperature denaturation peak at $53^{\circ} \mathrm{C}$ to denaturation of GOx monomers, and the higher temperature denaturation peak at $61^{\circ} \mathrm{C}$ to denaturation of GOx dimers.

We hypothesized that changes in GOx glycosylation resulting from the selected mutations could be responsible for the enhanced activity and thermal stability. With the introduction of a threonine residue, the A16T mutation in M2 introduces a candidate residue for O-linked glycosylation. The other isolated mutations resulted in introduction of a proline in place of leucine at position 9 or 13 (Figure 3B) directly adjacent to a serine residue, which is also a potential O-linked glycosylation site (Kukuruzinska et al., 1987). We found that digestion of WT, M1, M2, and M3 glycoproteins using endoglycosidase-H to cleave N-linked high mannose chains resulted in differently sized bands for M1-M3 as compared with WT when analyzed using SDS-PAGE 
(Figure 5), suggesting that O-linked glycosylation of the mutants conferred activity and stability enhancement. Since availability for glycosylation depends on structure, we can speculate that the L9P and L13P mutations resulted in disordering of the alpha helix linker region and improved accessibility of the adjacent serine residues for O-mannosyltransferases, resulting in stabilization of the dimerized form of GOx.

\section{Conclusion}

We presented a system where localized GOx-mediated hydrogel polymerization at the cell surface provided an artificial cell phenotype that was utilized for directed evolution of the enzymatic initiator. The technique allowed screening of GOx libraries using one-pot encapsulation reactions in homogeneous medium. The screening procedure consisted of only 10 minutes incubation of the mutant library followed by washing and flow cytometric sorting, without requiring additional reaction compartmentalization or robotic sampling. The potential throughput for screening enzymes is limited in this case only by the speed of flow cytometry ( $\sim 10^{7}$ cells/hour). This level of throughput significantly accelerates the enzyme screening step as compared to competing methods. In addition to GOx, other classes of enzymes are compatible with similar reaction schemes to achieve cross-linking of synthetic hydrogels for directed evolution, including other oxidoreductases, peroxidases, and laccases. We validated our system by screening and successfully isolating several stable GOx mutants exhibiting up to 4.9-fold higher catalytic efficiency which was achieved through large improvements of $k_{\text {cat }}$ and comparatively smaller improvements in $K_{\mathrm{m}}$. We characterized the differences in thermal stability and glycosylation profiles of the mutant enzymes to account for their ability to outperform the wild type under the assay conditions. Previously, a mutant Aga2-GOx called B11 was purified and characterized (Blazic et al., 2013 ) with $k_{\mathrm{cat}}=80 \mathrm{~s}^{-1}, \mathrm{~K}_{\mathrm{M}}=16 \mathrm{mM}$, and catalytic efficiency $=5.0$. Our Aga2-GOx mutant M1 reported here by comparison exhibits $k_{\mathrm{cat}}=136.1 \mathrm{~s}^{-1}, \mathrm{~K}_{\mathrm{M}}=10.68 \mathrm{mM}$, and catalytic efficiency $=12.74$. Meanwhile our Aga2-GOx mutant M3 exhibits $k_{\mathrm{cat}}=197.2 \mathrm{~s}^{-1}, \mathrm{~K}_{\mathrm{M}}=16.76 \mathrm{mM}$, and catalytic efficiency $=11.76$. We demonstrated that the cell encapsulation system works for WT-GOx and GOx mutants with catalytic turnover numbers $\left(k_{c a t}\right)$ in a range of $\sim 50-200 \mathrm{~s}^{-1}$. To adapt the system to enzymes with significantly lower turnover rates, further optimization would be necessary. Our approach of enzyme-mediated polymerization provides an important selection tool for the directed evolution campaigns of many industrially and medically relevant oxidoreductase enzymes. 


\section{Competing financial interests}

The authors declare no competing financial interests.

\section{Materials \& Correspondence}

*Correspondence and material requests to michael.nash@unibas.ch

\section{Associated content}

Supporting information. Additional experimental results and supporting analysis.

\section{Acknowledgments}

We thank Ivan Urosev for assistance with ${ }^{1} \mathrm{H}-\mathrm{NMR}$ measurements and data analysis. We thank Fabian Rudolf for consultation on library construction and transformation. We thank Florian Seebeck and Markus Aebi for helpful discussions. This work was funded by a Human Frontier Science Program (HFSP) Young Investigator Grant (RGY80/2015), by the National Center for Competence in Research Molecular Systems Engineering (NCCR-MSE), and by an ERC Starting Grant (MMA - 715207).

\section{References}

Aitken CE, Marshall RA, Puglisi JD. 2008. An oxygen scavenging system for improvement of dye stability in single-molecule fluorescence experiments. Biophys. J. 94:1826-1835.

Arnold FH. 2018. Directed Evolution: Bringing New Chemistry to Life. Angew. Chem. Int. Ed Engl. 57:4143-4148.

Blazic M, Kovacevic G, Prodanovic O, Ostafe R, Gavrovic-Jankulovic M, Fischer R, Prodanovic R. 2013. Yeast surface display for the expression, purification and characterization of wild-type and B11 mutant glucose oxidases. Protein Expr. Purif. 89:175-180.

Boder ET, Wittrup KD. 1997. Yeast surface display for screening combinatorial polypeptide libraries. Nat. Biotechnol. 15:553-557.

Chapman R, Gormley AJ, Herpoldt K-L, Stevens MM. 2014. Highly Controlled Open Vessel RAFT Polymerizations by Enzyme Degassing. Macromolecules 47:8541-8547.

Chen I, Dorr BM, Liu DR. 2011. A general strategy for the evolution of bond-forming enzymes using yeast display. Proc. Natl. Acad. Sci. U. S. A. 108:11399-11404.

Colin P-Y, Zinchenko A, Hollfelder F. 2015. Enzyme engineering in biomimetic compartments. Curr. Opin. Struct. Biol. 33:42-51.

Denard CA, Ren H, Zhao H. 2015. Improving and repurposing biocatalysts via directed evolution. Curr. Opin. Chem. Biol. 25:55-64. 
Fischlechner M, Schaerli Y, Mohamed MF, Patil S, Abell C, Hollfelder F. 2014. Evolution of enzyme catalysts caged in biomimetic gel-shell beads. Nat. Chem. 6:791-796.

Gietz RD, Woods RA. 2002. Transformation of yeast by lithium acetate/single-stranded carrier DNA/polyethylene glycol method. Methods Enzymol. 350:87-96.

Gonzalez-Perez D, Garcia-Ruiz E, Alcalde M. 2012. Saccharomyces cerevisiae in directed evolution: An efficient tool to improve enzymes. Bioeng. Bugs 3:172-177.

Griffiths AD, Tawfik DS. 2006. Miniaturising the laboratory in emulsion droplets. Trends Biotechnol. 24:395-402.

Holland JT, Harper JC, Dolan PL, Manginell MM, Arango DC, Rawlings JA, Apblett CA, Brozik SM. 2012. Rational redesign of glucose oxidase for improved catalytic function and stability. PLoS One 7:e37924.

Jeschek M, Reuter R, Heinisch T, Trindler C, Klehr J, Panke S, Ward TR. 2016. Directed evolution of artificial metalloenzymes for in vivo metathesis. Nature 537:661-665.

Kieke MC, Cho BK, Boder ET, Kranz DM, Wittrup KD. 1997. Isolation of anti-T cell receptor scFv mutants by yeast surface display. Protein Eng. 10:1303-1310.

Kintses B, Hein C, Mohamed MF, Fischlechner M, Courtois F, Lainé C, Hollfelder F. 2012. Picoliter cell lysate assays in microfluidic droplet compartments for directed enzyme evolution. Chem. Biol. 19:1001-1009.

Kukuruzinska MA, Bergh ML, Jackson BJ. 1987. Protein glycosylation in yeast. Annu. Rev. Biochem. 56:915-944.

Lipovsek D, Antipov E, Armstrong KA, Olsen MJ, Klibanov AM, Tidor B, Wittrup KD. 2007. Selection of horseradish peroxidase variants with enhanced enantioselectivity by yeast surface display. Chem. Biol. 14:1176-1185.

Liu Y, Sakai S, Kawa S, Taya M. 2014. Identification of hydrogen peroxide-secreting cells by cytocompatible coating with a hydrogel membrane. Anal. Chem. 86:11592-11598.

Lülsdorf N, Pitzler C, Biggel M, Martinez R, Vojcic L, Schwaneberg U. 2015. A flow cytometer-based whole cell screening toolbox for directed hydrolase evolution through fluorescent hydrogels. Chem. Commun. 51:8679-8682.

Malinowska KH, Nash MA. 2016. Enzyme- and affinity biomolecule-mediated polymerization systems for biological signal amplification and cell screening. Curr. Opin. Biotechnol. 39:68-75.

Malinowska KH, Rind T, Verdorfer T, Gaub HE, Nash MA. 2015. Quantifying Synergy, Thermostability, and Targeting of Cellulolytic Enzymes and Cellulosomes with Polymerization-Based Amplification. Anal. Chem. 87:7133-7140.

Malinowska KH, Verdorfer T, Meinhold A, Milles LF, Funk V, Gaub HE, Nash MA. 2014. Redox-Initiated Hydrogel System for Detection and Real-Time Imaging of Cellulolytic Enzyme Activity. ChemSusChem 7:2825-2831.

Oldenburg KR, Vo KT, Michaelis S, Paddon C. 1997. Recombination-mediated PCR-directed plasmid construction in vivo in yeast. Nucleic Acids Res. 25:451-452.

Ostafe R, Prodanovic R, Nazor J, Fischer R. 2014. Ultra-High-Throughput Screening Method for the Directed Evolution of Glucose Oxidase. Chem. Biol. 21:414-421.

Packer MS, Liu DR. 2015. Methods for the directed evolution of proteins. Nat. Rev. Genet. 16:379-394.

Pitzler C, Wirtz G, Vojcic L, Hiltl S, Böker A, Martinez R, Schwaneberg U. 2014. A Fluorescent HydrogelBased Flow Cytometry High-Throughput Screening Platform for Hydrolytic Enzymes. Chem. Biol. 21:1733-1742.

Powell KA, Ramer SW, Del Cardayré SB, Stemmer WPC, Tobin MB, Longchamp PF, Huisman GW. 2001. Directed Evolution and Biocatalysis. Angew. Chem. Int. Ed Engl. 40:3948-3959.

Prodanovic R, Radivoje P, Raluca O, Andreea S, Ulrich S. 2011. Ultrahigh Throughput Screening System for Directed Glucose Oxidase Evolution in Yeast Cells. Comb. Chem. High Throughput Screen. 14:5560.

Sakai S, Kawakami K. 2007. Synthesis and characterization of both ionically and enzymatically crosslinkable alginate. Acta Biomater. 3:495-501.

Sakai S, Komatani K, Taya M. 2012. Glucose-triggered co-enzymatic hydrogelation of aqueous polymer solutions. RSC Adv. 2:1502-1507.

Sakai S, Tsumura M, Inoue M, Koga Y, Fukano K, Taya M. 2013. Polyvinyl alcohol-based hydrogel dressing gellable on-wound via a co-enzymatic reaction triggered by glucose in the wound exudate. $J$. Mater. Chem. B Mater. Biol. Med. 1:5067.

Shoda S-I, Uyama H, Kadokawa J-I, Kimura S, Kobayashi S. 2016. Enzymes as Green Catalysts for 
Precision Macromolecular Synthesis. Chem. Rev. 116:2307-2413.

Sigg SJ, Seidi F, Renggli K, Silva TB, Kali G, Bruns N. 2011. Horseradish Peroxidase as a Catalyst for Atom Transfer Radical Polymerization. Macromol. Rapid Commun. 32:1710-1715.

Sjostrom SL, Bai Y, Huang M, Liu Z, Nielsen J, Joensson HN, Andersson Svahn H. 2014. High-throughput screening for industrial enzyme production hosts by droplet microfluidics. Lab Chip 14:806-813.

Swoboda BEP, Massey V. 1965. Purification and Properties of the Glucose Oxidase from Aspergillus niger. J. Biol. Chem. 240:2209-2215.

Tawfik DS, Griffiths AD. 1998. Man-made cell-like compartments for molecular evolution. Nat. Biotechnol. 16:652-656.

Taylor SV, Kast P, Hilvert D. 2001. Investigating and Engineering Enzymes by Genetic Selection. Angew. Chem. Int. Ed Engl. 40:3310-3335.

Uyama H, Kurioka H, Kobayashi S. 1997. Novel Bienzymatic Catalysis System for Oxidative Polymerization of Phenols. Polym. J. 29:190-192.

Vanella R, Bazin A, Ta DT, Nash MA. 2019. Genetically Encoded Stimuli-Responsive Cytoprotective Hydrogel Capsules for Single Cells Provide Novel Genotype-Phenotype Linkage. Chem. Mater. https://doi.org/10.1021/acs.chemmater.8b04348.

Wong CM, Wong KH, Chen XD. 2008. Glucose oxidase: natural occurrence, function, properties and industrial applications. Appl. Microbiol. Biotechnol. 78:927-938.

Zavada SR, Battsengel T, Scott TF. 2016. Radical-Mediated Enzymatic Polymerizations. Int. J. Mol. Sci. 17. http://dx.doi.org/10.3390/ijms17020195.

Zhu Z, Wang M, Gautam A, Nazor J, Momeu C, Prodanovic R, Schwaneberg U. 2007. Directed evolution of glucose oxidase from Aspergillus niger for ferrocenemethanol-mediated electron transfer. Biotechnol. J. 2:241-248. 
Tables

\begin{tabular}{|c|c|}
\hline Name & Sequence (5'-3') \\
\hline $\mathbf{F 1}$ & GCATACGGATCCATGCAGACTCTCCTTGTGAGCTCGC \\
\hline $\mathbf{R 1}$ & GCATACCTCGAGCTGCATGGAAGCATAATCTTCC \\
\hline $\mathbf{F 2}$ & TCGGGATCTGTACGACGATGACGATAAGGTACCAGGATCCATG \\
\hline $\mathbf{R 2}$ & CAGGATGCGTTGAAGTAGTGGCCAGCAGCGATCTGTTTGGC \\
\hline $\mathbf{F 3}$ & GCCAAACATATCGCTGCTGGCCACTACTTCAACGCATCCTG \\
\hline $\mathbf{R 3}$ & CATGGATCCTGGTACCTTATCGTCATCGTCGTACAGATCC \\
\hline
\end{tabular}

Table 1. List of DNA primers used in this work. 


\section{Figures}

A

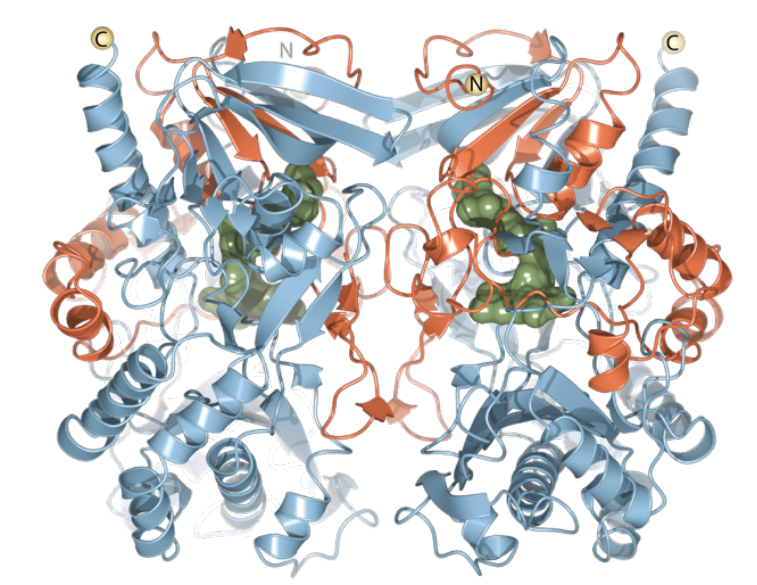

C
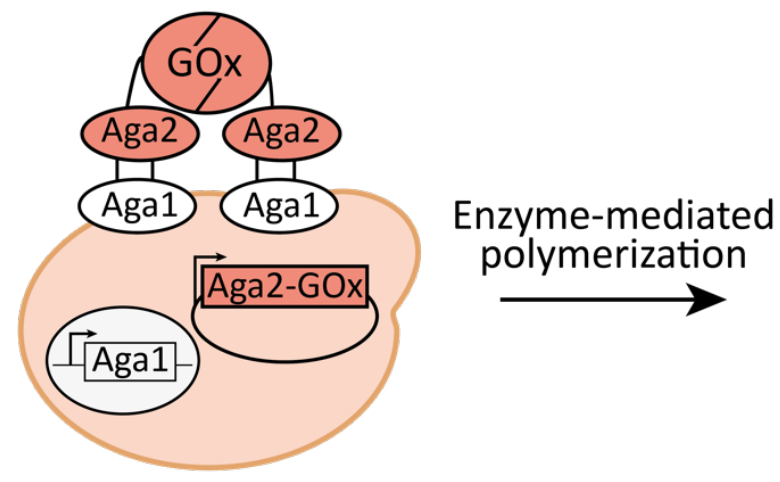

B
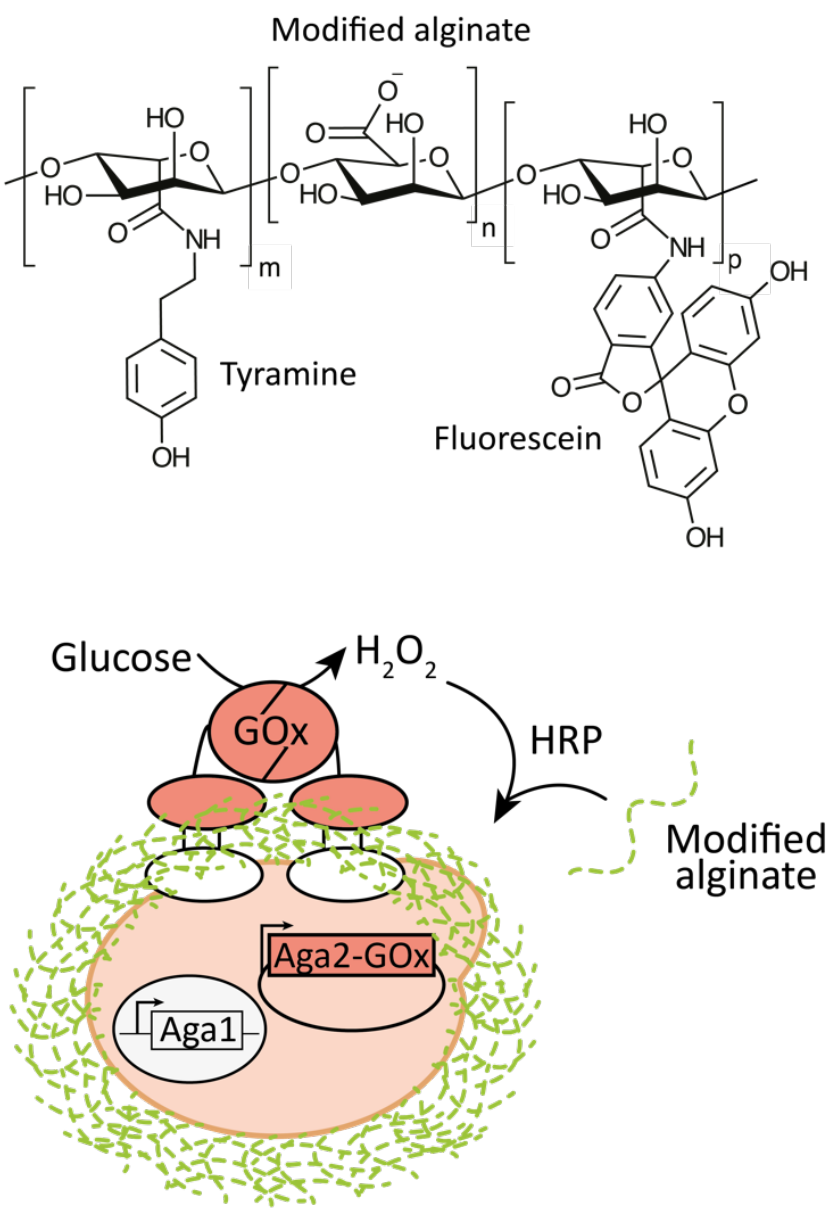

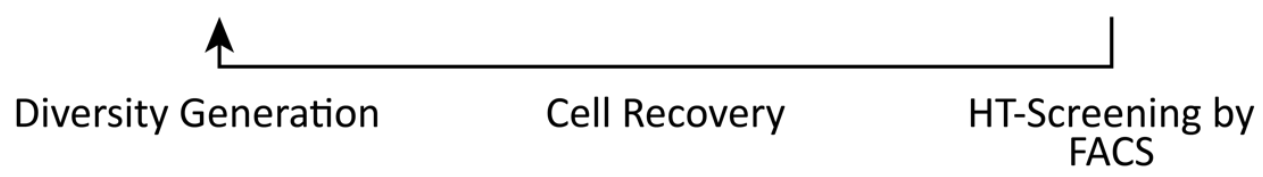

Figure 1. Overview of GOx directed evolution using enzymatic hydrogel polymerization. (A) Structural model of GOx homodimer from A. niger (PDB code $1 \mathrm{cf} 3$ ). The $\mathrm{N}$-terminal residues subjected to genetic diversification are highlighted in orange. The constant region residues are shown in blue. The FAD cofactor is shown as a surface plot in green. (B) Chemical structure of modified alginate used for cell encapsulation. (C) Scheme depicting gene induction and yeast display of GOx homodimer, followed by enzyme-mediated crosslinking of phenolated fluorescent alginate into a conformal hydrogel surrounding the cell. 
A

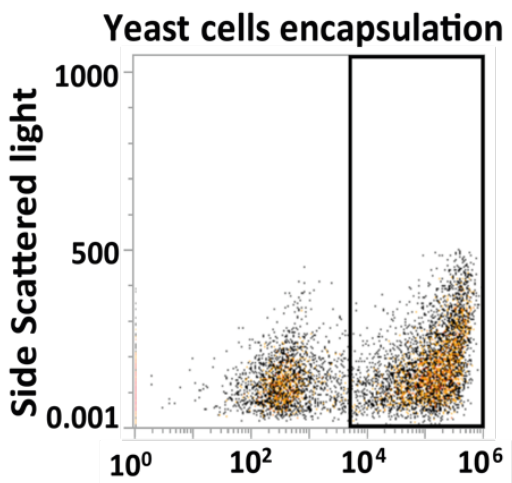

BL1- (green fluorescence)

B
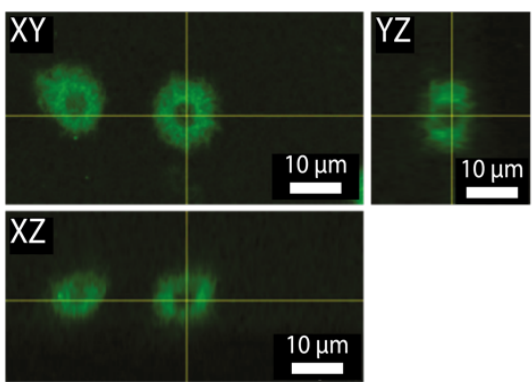

$0 \mu \mathrm{m}$

Figure 2. Yeast cells encapsulated in fluorescent alginate. (A) Flow cytometry plot of a yeast cell population displaying GOx and coated with fluorescent hydrogel. (B) Scanning confocal fluorescence microscopy images of single yeast cells encapsulated in fluorescent alginate shells. 
A

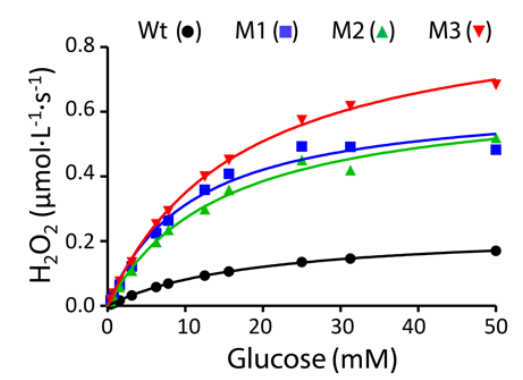

\begin{tabular}{|c|c|c|c|c|}
\hline Sample & Mutation & $\begin{array}{c}K_{\mathrm{m}} \\
(\mathrm{mM})\end{array}$ & $\begin{array}{l}k_{\text {cat }} \\
\left(s^{-1}\right)\end{array}$ & $\underset{\substack{k_{c a l} / K_{m} \\
\left(s^{-1} \cdot m^{-1}\right)}}{ }$ \\
\hline Wt & - & $\begin{array}{l}19.08 \\
( \pm 0.34)\end{array}$ & $\begin{array}{l}49.82 \\
( \pm 0.41)\end{array}$ & 2.61 \\
\hline M1 & L9P & $\begin{array}{l}10.68 \\
( \pm 1.67)\end{array}$ & $\begin{array}{c}136.10 \\
( \pm 7.97)\end{array}$ & 12.74 \\
\hline M2 & L13P-A16T & $\begin{array}{l}14.67 \\
( \pm 1.62)\end{array}$ & $\begin{array}{c}140.90 \\
( \pm 6.50)\end{array}$ & 9.60 \\
\hline M3 & L13P & $\begin{array}{l}16.76 \\
( \pm 0.77)\end{array}$ & $\begin{array}{c}197.20 \\
( \pm 3.99)\end{array}$ & 11.76 \\
\hline
\end{tabular}

C

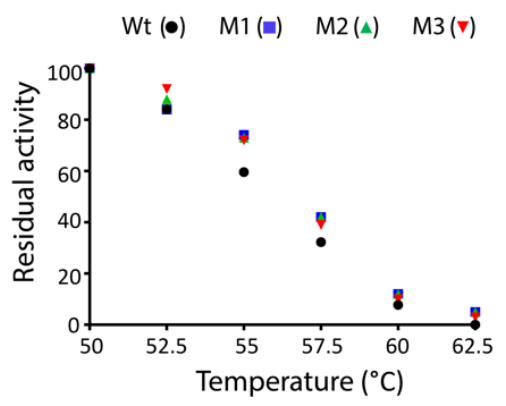

Figure 3. Kinetic parameters and thermal stability of WT and evolved mutant GOx. (A) Kinetic plots showing initial rates of product formation vs. substrate concentration for WT and mutant GOx. (B) Mutation sites and kinetic parameters for WT and mutant GOx. (C) Thermostability of WT and mutant GOx was compared using normalized initial activity following heat shock at a given temperature $(n=3)$. 


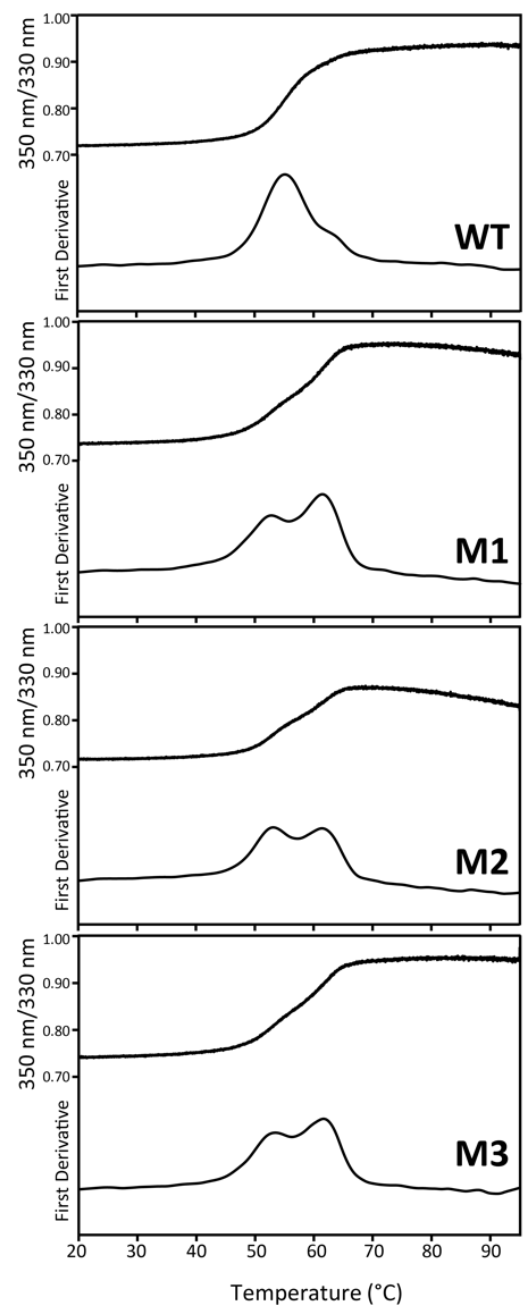

Figure 4. Thermal denaturation curves of GOx wild type (WT) and mutant enzymes (M1, M2, M3). Changes in the fluorescence emission ratio $(350 \mathrm{~nm} / 330 \mathrm{~nm}$ ) excited at $280 \mathrm{~nm}$ were detected using the Prometheus NT.48. Each experiment was run in triplicate at a protein concentration of $0.1 \mathrm{mg} / \mathrm{ml}$. Curves show the average of 3 runs. 


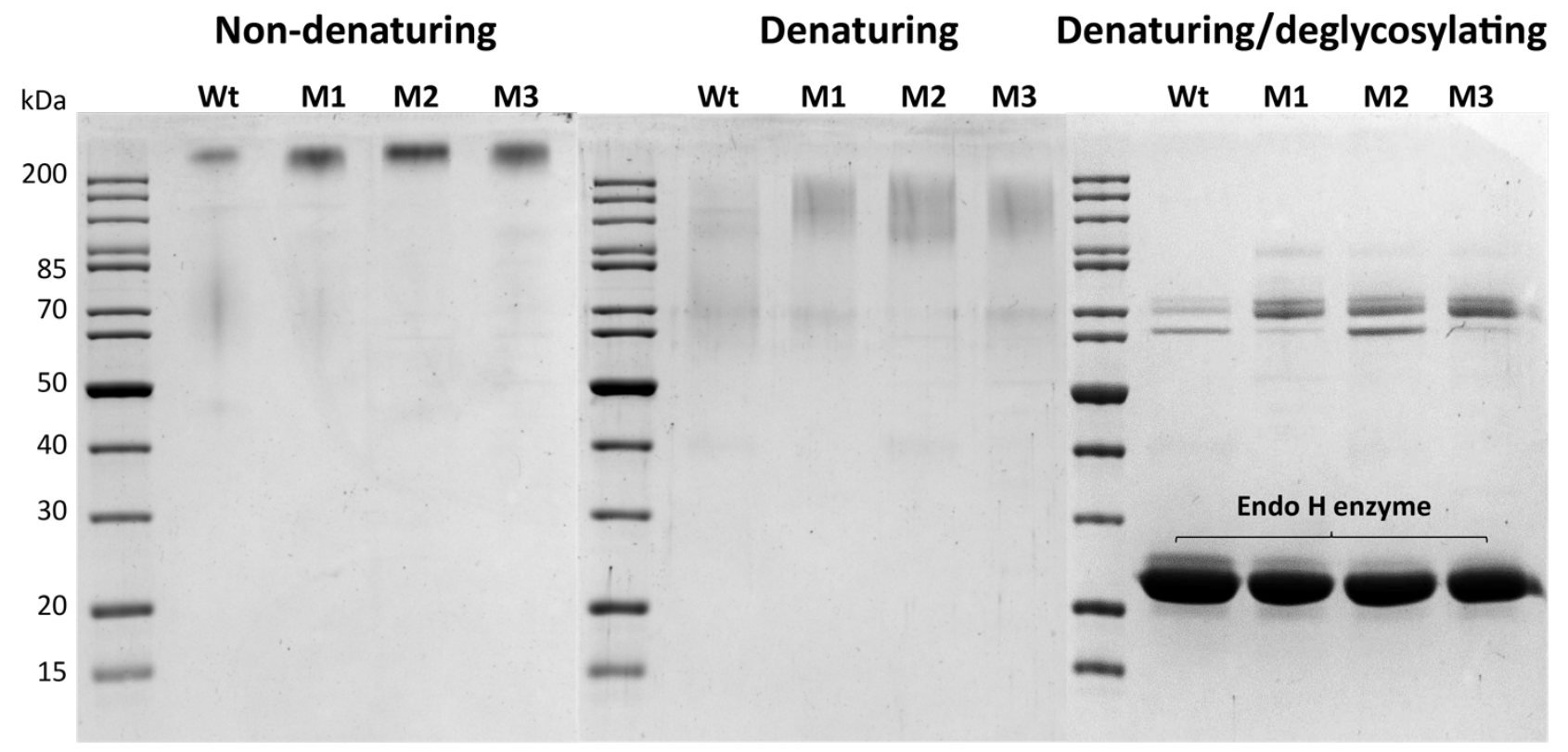

Figure 5. SDS-PAGE of purified Aga2-GOx wt, M1, M2, and M3 fusion proteins. Each sample (1 $\mu \mathrm{g})$ was loaded respectively in non-denaturing form, after denaturation with 2-Mercaptoethanol and incubation at $95^{\circ} \mathrm{C}$, or after denaturation and incubation for 1 hour with 1000 units of EndoH enzyme. The glycosylated samples appear as smears due to variations in glycosylation levels. Treatment with EndoH caused cleavage of chitobiose from high mannose and some hybrid $\mathrm{N}$-linked oligosaccharides revealing a more defined pattern as compared with the wild type. 


\section{SUPPORTING INFORMATION}

Enzyme-mediated hydrogel encapsulation of single cells for highthroughput screening and directed evolution of oxidoreductases

Rosario Vanella ${ }^{1,2}$, Duy Tien $\mathrm{Ta}^{1,2,3}$, and Michael A. Nash ${ }^{1,2}$ *

${ }^{1}$ Department of Chemistry, University of Basel, 4058 Basel, Switzerland.

${ }^{2}$ Department of Biosystems Science and Engineering, ETH Zurich, 4058 Basel, Switzerland.

${ }^{3}$ Current affiliation: A*STAR - Agency for Science, Technology and Research, 138632 Singapore.

*Correspondence to michael.nash@unibas.ch 


\section{Protein sequences}

Amino acid changes relative to the wild type sequence of Glucose Oxidase are highlighted red.

Aga2p_GOx (wild type)

$\varepsilon_{280}=104,170 \mathrm{M}^{-1} \mathrm{~cm}^{-1}$

MQLLRCFSIFSVIASVLAQELTTICEQIPSPTLESTPYSLSTTTILANGKAMQGVFEYYK SVTFVSNCGSHPSTTSKGSPINTQYVFKLLQASGGGGSGGGGSGGGGSASMTGGQQMGRDL YDDDDKVPGSMQTLLVSSLVVSLAAALPHYIRSNGIEASLLTDPKDVSGRTVDYIIAGGGLTG LTTAARLTENPNISVLVIESGSYESDRGPIIEDLNAYGDIFGSSVDHAYETVELATNNQTALIRS GNGLGGSTLVNGGTWTRPHKAQVDSWETVFGNEGWNWDNVAAYSLQAERARAPNAKQIA AGHYFNASCHGVNGTVHAGPRDTGDDYSPIVKALMSAVEDRGVPTKKDFGCGDPHGVSMF PNTLHEDQVRSDAAREWLLPNYQRPNLQVLTGQYVGKVLLSQNGTTPRAVGVEFGTHKGN THNVYAKHEVLLAAGSAVSPTILEYSGIGMKSILEPLGIDTVVDLPVGLNLQDQTTATVRSRIT SAGAGQGQAAWFATFNETFGDYSEKAHELLNTKLEQWAEEAVARGGFHNTTALLIQYENY RDWIVNHNVAYSELFLDTAGVASFDVWDLLPFTRGYVHILDKDPYLHHFAYDPQYFLNELD LLGQAAATQLARNISNSGAMQTYFAGETIPGDNLAYDADLSAWTEYIPYHFRPNYHGVGTCS MMPKEMGGVVDNAARVYGVQGLRVIDGSIPPTQMSSHVMTVFYAMALKISDAILEDYASM Q LESRGPFEGKPIPNPLLGLDSTRTG HHHHHH*

\section{Aga2p_GOx (Mutant 1)}

$\boldsymbol{E}_{280}=104,170 \mathrm{M}^{-1} \mathrm{~cm}^{-1}$

MQLLRCFSIFSVIASVLAQELTTICEQIPSPTLESTPYSLSTTTILANGKAMQGVFEYYK SVTFVSNCGSHPSTTSKGSPINTQYVFKLLQASGGGGSGGGGSGGGGSASMTGGQQMGRDL YDDDDKVPGSMQTLLVSSPVVSLAAALPHYIRSNGIEASLLTDPKDVSGRTVDYIIAGGGLTG LTTAARLTENPNISVLVIESGSYESDRGPIIEDLNAYGDIFGSSVDHAYETVELATNNQTALIRS GNGLGGSTLVNGGTWTRPHKAQVDSWETVFGNEGWNWDNVAAYSLQAERARAPNAKQIA AGHYFNASCHGVNGTVHAGPRDTGDDYSPIVKALMSAVEDRGVPTKKDFGCGDPHGVSMF PNTLHEDQVRSDAAREWLLPNYQRPNLQVLTGQYVGKVLLSQNGTTPRAVGVEFGTHKGN THNVYAKHEVLLAAGSAVSPTILEYSGIGMKSILEPLGIDTVVDLPVGLNLQDQTTATVRSRIT SAGAGQGQAAWFATFNETFGDYSEKAHELLNTKLEQWAEEAVARGGFHNTTALLIQYENY RDWIVNHNVAYSELFLDTAGVASFDVWDLLPFTRGYVHILDKDPYLHHFAYDPQYFLNELD LLGQAAATQLARNISNSGAMQTYFAGETIPGDNLAYDADLSAWTEYIPYHFRPNYHGVGTCS MMPKEMGGVVDNAARVYGVQGLRVIDGSIPPTQMSSHVMTVFYAMALKISDAILEDYASM Q LESRGPFEGKPIPNPLLGLDSTRTG HHHHHH* 
MQLLRCFSIFSVIASVLAQELTTICEQIPSPTLESTPYSLSTTTILANGKAMQGVFEYYK SVTFVSNCGSHPSTTSKGSPINTQYVFKLLQASGGGGSGGGGSGGGGSASMTGGQQMGRDL YDDDDKVPGSMQTLLVSSLVVSPAATLPHYIRSNGIEASLLTDPKDVSGRTVDYIIAGGGLTG LTTAARLTENPNISVLVIESGSYESDRGPIIEDLNAYGDIFGSSVDHAYETVELATNNQTALIRS GNGLGGSTLVNGGTWTRPHKAQVDSWETVFGNEGWNWDNVAAYSLQAERARAPNAKQIA AGHYFNASCHGVNGTVHAGPRDTGDDYSPIVKALMSAVEDRGVPTKKDFGCGDPHGVSMF PNTLHEDQVRSDAAREWLLPNYQRPNLQVLTGQYVGKVLLSQNGTTPRAVGVEFGTHKGN THNVYAKHEVLLAAGSAVSPTILEYSGIGMKSILEPLGIDTVVDLPVGLNLQDQTTATVRSRIT SAGAGQGQAAWFATFNETFGDYSEKAHELLNTKLEQWAEEAVARGGFHNTTALLIQYENY RDWIVNHNVAYSELFLDTAGVASFDVWDLLPFTRGYVHILDKDPYLHHFAYDPQYFLNELD LLGQAAATQLARNISNSGAMQTYFAGETIPGDNLAYDADLSAWTEYIPYHFRPNYHGVGTCS MMPKEMGGVVDNAARVYGVQGLRVIDGSIPPTQMSSHVMTVFYAMALKISDAILEDYASM Q LESRGPFEGKPIPNPLLGLDSTRTG HHHHHH*

\section{Aga2p_GOx (Mutant 3)}

$$
\varepsilon_{280}=104,170 \mathrm{M}^{-1} \mathrm{~cm}^{-1}
$$

MQLLRCFSIFSVIASVLAQELTTICEQIPSPTLESTPYSLSTTTILANGKAMQGVFEYYK SVTFVSNCGSHPSTTSKGSPINTQYVFKLLQASGGGGSGGGGSGGGGSASMTGGQQMGRDL YDDDDKVPGSMQTLLVSSLVVSPAAALPHYIRSNGIEASLLTDPKDVSGRTVDYIIAGGGLTG LTTAARLTENPNISVLVIESGSYESDRGPIIEDLNAYGDIFGSSVDHAYETVELATNNQTALIRS GNGLGGSTLVNGGTWTRPHKAQVDSWETVFGNEGWNWDNVAAYSLQAERARAPNAKQIA AGHYFNASCHGVNGTVHAGPRDTGDDYSPIVKALMSAVEDRGVPTKKDFGCGDPHGVSMF PNTLHEDQVRSDAAREWLLPNYQRPNLQVLTGQYVGKVLLSQNGTTPRAVGVEFGTHKGN THNVYAKHEVLLAAGSAVSPTILEYSGIGMKSILEPLGIDTVVDLPVGLNLQDQTTATVRSRIT SAGAGQGQAAWFATFNETFGDYSEKAHELLNTKLEQWAEEAVARGGFHNTTALLIQYENY RDWIVNHNVAYSELFLDTAGVASFDVWDLLPFTRGYVHILDKDPYLHHFAYDPQYFLNELD LLGQAAATQLARNISNSGAMQTYFAGETIPGDNLAYDADLSAWTEYIPYHFRPNYHGVGTCS MMPKEMGGVVDNAARVYGVQGLRVIDGSIPPTQMSSHVMTVFYAMALKISDAILEDYASM Q LESRGPFEGKPIPNPLLGLDSTRTG HHHHHH* 


\section{A}

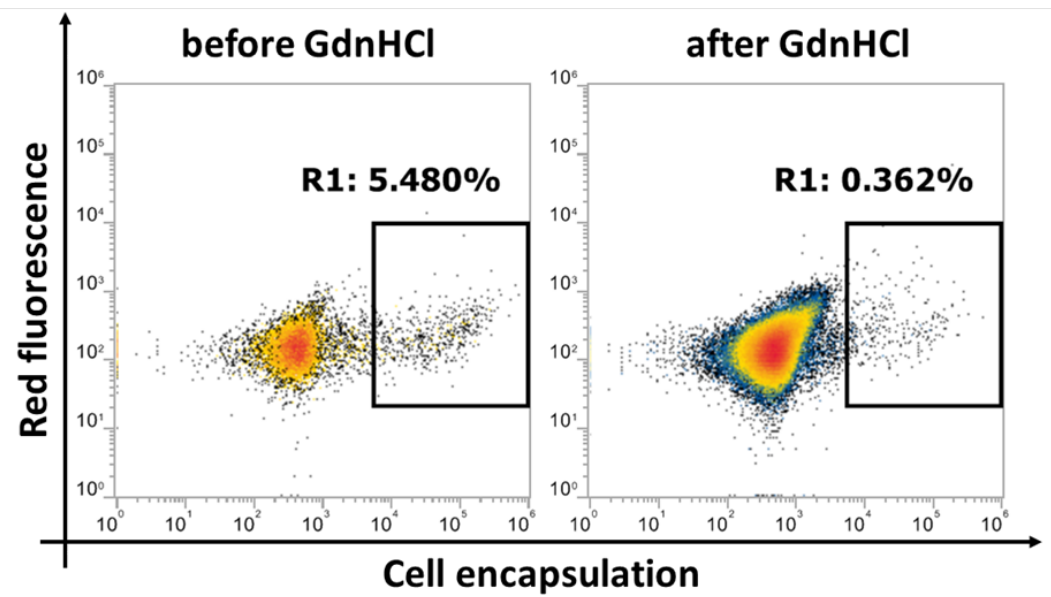

B

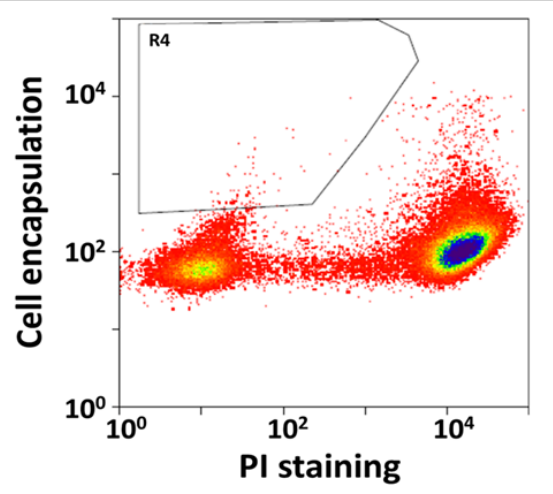

Figure S1. (A) Flow cytometric plot of the GOx mutant library encapsulated with green fluorescent alginate before and after treatment with guanidium chloride ( $\mathrm{GdnHCl})$. Gate R1 surrounds the cells displaying functional GOx that have been encapsulated with modified alginate. The plot "before GdnHCl" shows 10,000 events. The plot "after GdnHCl" shows 90,000 single events in order for the gated events to be easily visible. (B) Flow cytometry analysis of the yeast gene mutant library incubated with 5M Guanidinium Chloride and treated with Propidium Iodide (PI) before being assayed through cell encapsulation for residual activity of Glucose Oxidase. The cells gated in R4 (positive for encapsulation in fluorescent alginate hydrogel and negative for PI) were sorted and recultured for the isolation of the evolved enzymes. 